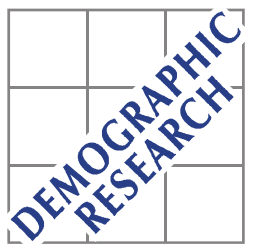

Demographic Research a free, expedited, online journal

of peer-reviewed research and commentary in the population sciences published by the Max Planck Institute for Demographic Research

Konrad-Zuse Str. 1, D-18057 Rostock · GERMANY

www.demographic-research.org

DEMOGRAPHIC RESEARCH

VOLUME 26, ARTICLE 19, PAGES 489-510

PUBLISHED 30 MAY 2012

http://www.demographic-research.org/Volumes/Vol26/19/

DOI: 10.4054/DemRes.2012.26.19

Descriptive Findings

Changes in educational differentials in old-age mortality in Finland and Sweden between

1971-1975 and 1996-2000

Virginia Zarulli

Domantas Jasilionis

Dmitri A. Jdanov

(C) 2012 Zarulli, Jasilionis \& Jdanov.

This open-access work is published under the terms of the Creative Commons

Attribution NonCommercial License 2.0 Germany, which permits use, reproduction \& distribution in any medium for non-commercial purposes, provided the original author(s) and source are given credit.

See http:// creativecommons.org/licenses/by-nc/2.0/de/ 


\section{Table of Contents}

1 Introduction $\quad 490$

2 Data and methods $\quad 491$

$3 \quad$ Results 493

4 Discussion $\quad 497$

5 Acknowledgments $\quad 501$

$\begin{array}{ll}\text { References } & 502\end{array}$

$\begin{array}{ll}\text { Appendix } & 506\end{array}$ 


\title{
Changes in educational differentials in old-age mortality in Finland and Sweden between 1971-1975 and 1996-2000
}

\author{
Virginia Zarulli ${ }^{1,2}$ \\ Domantas Jasilionis ${ }^{2}$ \\ Dmitri A. Jdanov ${ }^{2,3}$
}

\begin{abstract}

\section{BACKGROUND}

The majority of the studies on developed countries confirm that socioeconomic mortality inequalities have been persisting or even widening. It has also been suggested that inequalities have increased at old ages.
\end{abstract}

\section{OBJECTIVE}

In this study we systematically assess the direction and magnitude of changes in mortality differences at old ages in Sweden and Finland over the period 1971 to 2000.

\section{METHODS}

The vast majority of the findings on mortality differentials rely on life table or aggregated mortality measures. However, conventional mean lifespan (life expectancy) hides important characteristics of the distribution of lifespan. Modal age at death and measures of disparity provide additional important insights into longevity, especially when focusing on mortality and survival at old ages. In this paper we use high quality census-linked data and both conventional life expectancy and distribution of life span measures.

\section{RESULTS}

We found that the educational gap in life expectancy at age 65 and the total amount of mortality inequality by education, as reflected by average inter-group difference, increased in both countries. With the exception of Swedish females, the corresponding gap in modal age at death decreased.

1 “La Sapienza” University of Rome, Department of Statistics, Rome, Italy.

${ }^{2}$ Max Planck Institute for Demographic Research, Rostock, Germany.

${ }^{3}$ New Economic School, Moscow, Russia. 


\section{CONCLUSIONS}

Although the results suggest that the life expectancy gap is largely explained by differential mortality due to cardiovascular system diseases, the role of other causes of death (especially cancers) has also increased.

\section{Introduction}

Several decades ago it was suggested that the emergence of universal welfare states might eventually lead to a decrease in health inequalities. However, the findings from national and international studies confirm that socioeconomic mortality differences remained at the same level or even increased in the majority of European countries, including the Nordic countries with strong egalitarian policies (Hattersley 1997; Kunst et al. 2004; Mackenbach 2006; Marmot and McDowall 1986; Shkolnikov et al. 2011; Strand et al. 2010; Valkonen 2001; Valkonen et al. 1993).

Most of the existing studies on health inequalities focus on adult ages. Meanwhile, several studies have confirmed that notable mortality differences also persist late in life (Hoffmann 2011; Huisman et al. 2004; Martelin 1994, 1996; Olausson 1991). There are only a few studies providing long-term data on the trends in socioeconomic inequalities in mortality at old ages. The prior findings based on the longitudinal data for Finland provide conflicting evidence about the direction of trends in inequalities at older ages. For example, Valkonen et al. (1993) have shown that, during the 1980s, educational differences in life expectancy at age 60 grew slightly for males but diminished for females. Martelin, Koskinen and Valkonen (1998) suggest that mortality differentials by education and occupation among the oldest-old (above age 80) remained unchanged throughout the 1970s and 1980s.

One of the most important obstacles to studying long-term trends in socioeconomic mortality differentials at old ages is the lack of reliable census-linked data. Such data covering longer periods are available only for a few countries. Thanks to a long history of population registers, the Nordic countries maintain census-linked databases dating back to the 1960s or 1970s. The majority of studies on mortality differentials use life table or aggregated mortality measures and provide simple range measures of inequality, such as mortality rate ratios or mortality rate difference. Recently more advanced measures such as slope index of inequality (SII), average inter-group difference (AID), or Gini coefficient have been increasingly used for studying mortality differentials (Shkolnikov et al. 2011).

With the increasing importance of "delayed aging" (Kannisto 2001) it has been understood that the conventional mean lifespan (life expectancy) measure may hide 
some characteristics of population health such as the most typical length of life (modal age at death) and specifics of the distribution of life span (Kannisto 2000, 2001; van Raalte et al. 2011). Both the mode and measures of life span disparity may be considered good alternatives for measuring survival at old ages, because they are much less dependent on child and premature mortality (Kannisto 2001). These two measures also provide important insights for studying old age related health issues such as survival at old ages and mortality compression (Canudas-Romo 2008; Cheung et al. 2005; Cheung and Robine 2007; Kannisto 2001). Considering differences in mode and life span inequality also sheds more light on socioeconomic mortality differentials. For example, van Raalte et al. (2011) have shown that lower socioeconomic groups have shorter life spans and, at the same time, show higher life span variation.

This study aims to assess the direction and the magnitude of changes in mortality differences by education at old ages in Sweden and Finland over the period from 1971 to 2000. Besides conventional life expectancy at age 65, modal age at death and the life span disparity measure were used to describe more thoroughly the specifics of old-age mortality within each education group. The changes in total amount of mortality inequality were assessed using average inter-group difference (AID), which accounts for mortality in all population groups and considers the population weights of each group. Finally, age- and cause- decomposition of life expectancy differences between low and high education groups was performed in order to shed more light on the changing causal mechanisms behind mortality inequality at old ages in both countries.

\section{Data and methods}

The census-linked mortality datasets were provided by Statistics Finland and Statistics Sweden. For Finland census-based information was linked with the death registration of the five calendar years after the 1970 and 1995 censuses. For Sweden the educationspecific counts on the deceased and survivors was obtained via linkage of deaths to the 1960 and 1990 censuses. The annual data for both countries covering each of the five (Finland) or ten (Sweden) follow-up years after the censuses were aggregated to the two five-year periods (1971-1975 and 1996-2000).

As a measure of social class we use education level, which refers to the human capital gained early in life (Mirowsky and Ross 2003). We chose two extreme and broad education classes (high and low education) to measure the magnitude of the life expectancy gap. We believe that this restriction avoids potential biases due to: 1) changes in education systems within each country 2) cross-country differences in education systems. The 'high' education category refers to individuals with completed university or college education, whereas the 'low' education category refers to those 
with lower than secondary education (or whose education is unknown). Similar definitions were applied in the previous Nordic studies (Valkonen 1993; Valkonen, Sihvonen and Lahelma 1997).

The distribution of deaths and person years of exposure is shown in Table 1.

Table 1: Person years and number of deaths (thousands) at age 65+ by sex and level of education in Finland and Sweden between 1971-1975 and 1996-2000

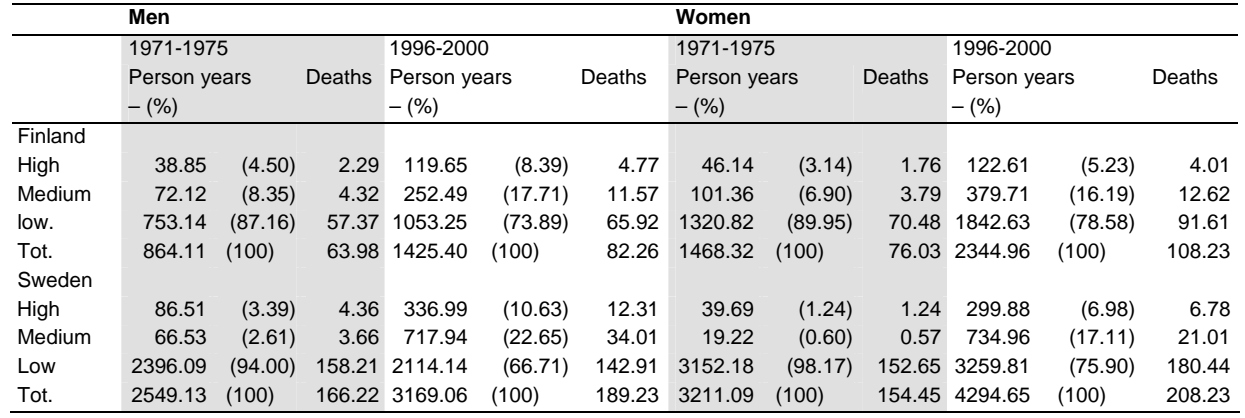

We grouped causes of death into the following categories: 1) cerebrovascular, circulatory diseases; 2) heart diseases; 3) lung cancer; 4) breast cancer (for women) or prostate cancer (for men); 5) stomach cancer; 6) intestine cancer; 7) uterus cancer (for women only); 8) other neoplasms; 9) mental disorders, and the diseases of the nervous system (including Alzheimer's disease), senility; 10) respiratory, infectious diseases; 11) other diseases; 12) accidental falls; 13) suicides; 14) other external causes; 15) illdefined, unknown causes. Table A1 in the Appendix provides detailed information about the selected causes of death (ICD8 codes for 1971-1975 and ICD10 codes for 1996-2000). The percentage of deaths due to ill-defined causes is very low in both countries (below $0.25 \%$ for both time points).

For both high and low education groups, life expectancy at age 65 and modal age at death (after age 65) were calculated using conventional methods (Chiang 1984; Kannisto 2001). The measure of life span disparity after age 65 (the shortest age interval in which $50 \%$ of all life table deaths after age 65 occur (C50)) was calculated according to the algorithm proposed by Kannisto (2000). This measure has an advantage over mode- or mean-based measures, such as standard deviation from the mode or inter-quartile range, because it is completely free from age scale and is more suitable for locating the greatest concentration of life table deaths (Kannisto 2000). As recommended by Kannisto (2000, 2001), the modal age at death and C50 measure were calculated using smoothed life table deaths. The standard function loess implemented in 
the program R (R Development Core Team 2010) was applied for this purpose, using a low degree of smoothing.

The age- and cause- decomposition of differences in life expectancy between high and low education groups was performed using the algorithm for decomposition of differences between aggregate demographic measures (Andreev, Shkolnikov and Begun 2002).

The full amount of mortality inequality was measured using average inter-group difference in mortality (AID). This measure is defined as the population-weighted average of mortality differences across all pairs of group-specific standardized death rates and measured as number of deaths per 1000 person years of exposure (Shkolnikov et al. 2011).

\section{Results}

Changes in remaining life expectancy at age 65

From 1971-75 to 1996-2000 male and female life expectancy at age 65 increased for both high and low education groups (Fig.1). However, there were notable differences in improvement by education group: highly educated males and females benefited from more rapid life expectancy increases than lower educated males and females. Highly educated Finnish males experienced the largest improvement (4.1 years), whereas low educated Swedish males showed the least progress (only 1.8 years). As a consequence the life expectancy gap increased. In Finland the gap grew notably only among males (from 1.9 to 3.2 years), whereas the increase was negligible for females (2.0 and 2.3 years, respectively). In Sweden the gap almost doubled for males (from 1.4 to 2.7 years) and increased by about 1.5 times for females (from 2.1 to 3.2 years).

Changes in modal age at death and life span disparity (after age 65)

Table 2 shows the changes in modal age at death (after age 65) in both countries between 1971-75 and 1996-2000. As expected, the modal age at death shifted to older ages from 1971-1975 to 1996-2000 for both education groups. The increase in male modal age at death was particularly significant for Finnish males (8.3-8.4 years for both education groups), whereas it was less important for Swedish males (1.9 and 4.2 years for high and low education groups, respectively).

The increase in female modal age at death was similar for both educational groups and countries (4-5 years). By the end of the period covered, highly educated males and females in both countries reached very advanced modal ages at death (around 85-86 years for males and 89-90 years for females). The modal age remained substantially lower for lower educated Finnish and Swedish males (81 and 83 years, respectively). 
This disadvantage was much less pronounced among lower educated females in both countries.

Figure 1: Trends in life expectancy at age 65 between 1971-1975 and 1996-2000
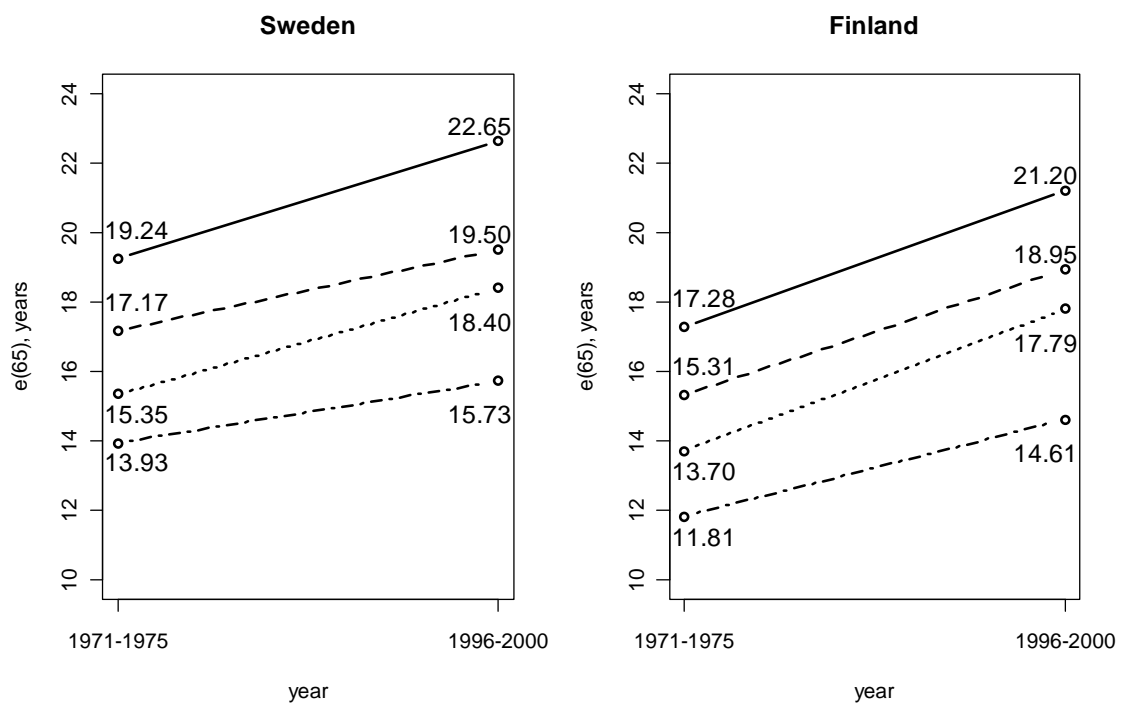

Men, High Education $\cdot \cdots \cdot \cdots \cdot$ Women, High Education - -
Men, Low Education -..... Women, Low Education ---

From 1971-75 to 1996-2000 the difference in modal age at death between high and low education groups decreased among Finnish women (from 3.7 to 2.6 years) and Swedish males (from 5.2 to 2.9 years). At the same time it remained almost the same for Finnish males (around 4.6 years) and slightly increased for Swedish females (from 1.7 to 2.1 years).

Table 2 points to contradictory changes in lifespan disparity (after age 65) within each educational group. In 1971-75, with the exception of Swedish females, lifespan variation was even higher in the high education group than in the low education group. In 1996-2000 life span disparity became higher in the low education group.

For males, disparity remained at the same level or slightly increased. The most notable growth was observed among Finnish males with low education, whereas highly educated Swedish males showed a moderate decrease (Table 2). Lifespan disparity for 
lower educated Finnish females and for both education groups among Swedish females remained at about the same level. At the same time highly educated Finnish females showed some decrease (Table 2).

Table 2: Modal age at death, shortest age interval within which $50 \%$ of life table deaths occur (C50) and their difference between high and low education groups, for men and women in Sweden and Finland in 1971-1975 and 1996-2000

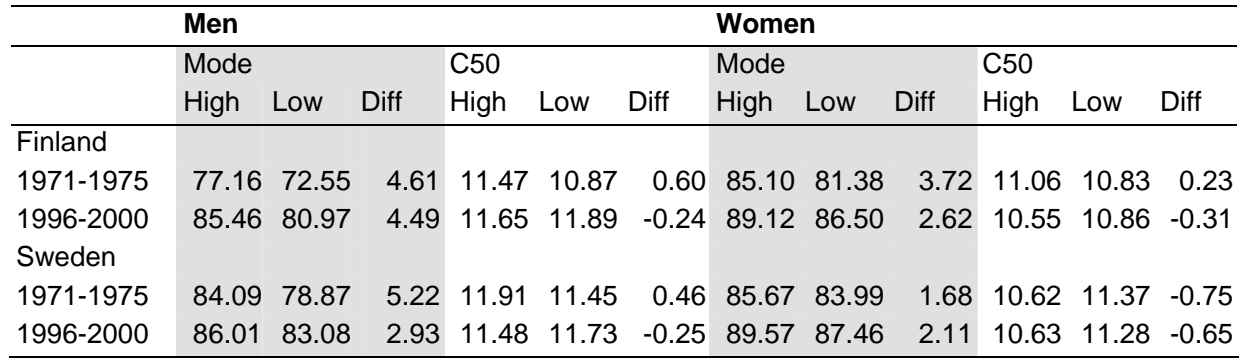

Age- and cause- contributions to the educational difference in the remaining life expectancy at age 65

Figure 2 shows age and cause contributions to the life expectancy gap between low and high education groups. To simplify the figure the 15 categories of causes of death have been aggregated into 10 groups (tables A2 and A3 in the Appendix report the contributions of the 15 causes of death). For males it can be seen that the educational gap in Finland is much more dependent on the mortality excess of lower educated males at younger ages (65-74 years), whereas the age-specific contributions in Sweden were more evenly distributed. Among females the overall life expectancy gap was more dependent on mortality differences at oldest ages. Furthermore, the contributions of these age groups to the educational difference increased over time (Fig. 2). 
Figure 2: Age-cause specific components of difference in life expectancy at age 65 between low educated group and highly educated group in 1971-1975 and 1996-2000

a) Men

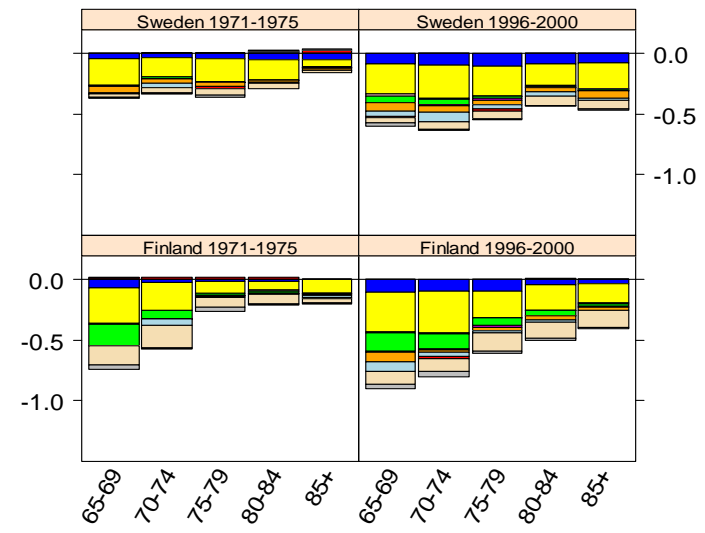

b) Women
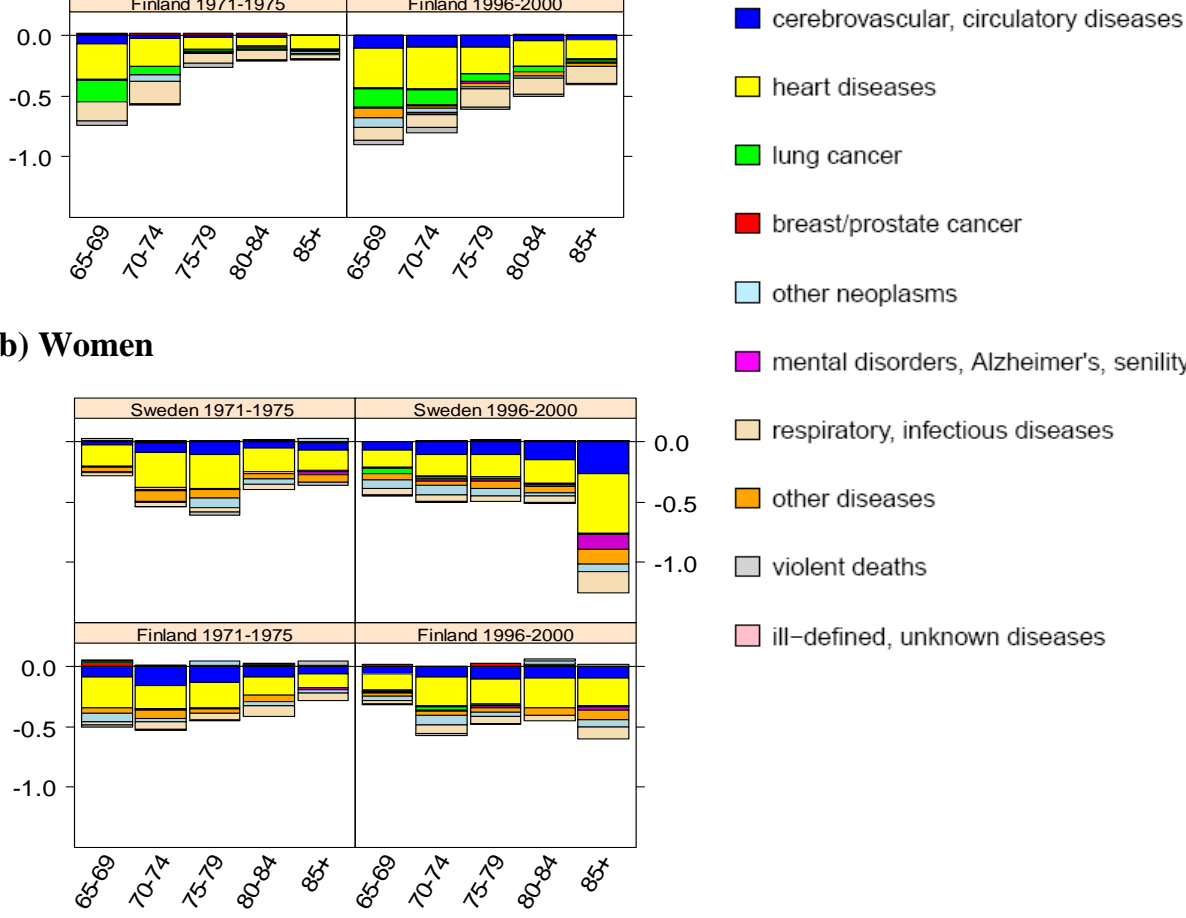

In respect to the contribution of causes of death, the two countries show some common features, but some differences can also be observed. As expected, cardiovascular system diseases (heart diseases, cerebrovascular system diseases, and other cardiovascular system diseases) represent the largest contribution to the life 
expectancy gap between high and low education groups at all ages. However, the overall share of cardiovascular diseases decreased over time. For example, in Sweden, they explained about $70 \%$ of the total male and female life expectancy gap in 1971-75, whereas thirty years later this contribution has decreased to $60 \%$. At the same time the importance of other causes increased. The shares of cancers (except lung, breast, and prostate cancer) grew in both countries. This growth was more pronounced for women than for men. In 1996-2000 this group of causes explained about $9 \%$ of the educational female life expectancy gap and about $6 \%$ of the male life expectancy gap. According to the literature (Strand et al. 2007), breast cancer usually shows an opposite social mortality gradient. Such a gradient persisted in Sweden and Finland for both time points. By contrast, the initial advantage of low educated men regarding mortality from prostate cancer disappeared.

The study also points to some differences between the two countries. The contribution of smoking-related lung cancers to male life expectancy difference between high and low education groups was much bigger in Finland (15\% in 1971-75 and $13 \%$ in 1996-2000) than in Sweden (less than 2\% in 1971-1975 and 5\% in 19962000). Among women, on the contrary, lung cancer represents a smaller contribution and shows a general tendency to reverse the pattern from a situation favorable to lower classes to one where the advantage disappears, in agreement with the "smoking epidemiological transition” (Lopez, Collishaw and Piha 1994).

As for other causes of death, respiratory and infectious diseases were also important components of the life expectancy gap, especially in Finland. Finally, we found that contributions of old age related diseases (mental disorders, Alzheimer's, and senility) increased. These causes of death seem to be more important for the female life expectancy gap, especially in Sweden, where their contribution grew from slightly more than $1 \%$ in $1971-1975$ to $6 \%$ in $1996-2000$.

\section{Discussion}

This study systematically examined changes in the educational gap in old age mortality in Finland and Sweden from 1971-75 to 1996-2000. In order to capture different aspects of survival at old ages we used two measures of longevity - life expectancy at 65 and modal age at death. In order to reveal possible relationships between changes in survival and the mortality compression process, we applied a measure of life span disparity - the shortest age interval in which $50 \%$ of life table deaths after age 65 occur. Simultaneous usage of the three aforementioned measures allows more objective assessment of survival at old ages than using one arbitrary chosen indicator. For 
example, Kannisto (2001) suggests that "as compression and rectangularization [of survival curve] advance, the mode becomes the central indicator of the length of life".

The findings show that the gap in life expectancy at age 65 increased for both sexes and in both countries. This confirms prior findings that socioeconomic mortality inequalities have also been widening at old ages. Interestingly, the educational differences in the most typical age at death (modal age at death) decreased for both sexes in Finland and for males in Sweden. These contradictory findings can be explained by peculiar features of the two measures, which capture different aspects of survival. First, life expectancy depends on mortality rates and distribution of life table deaths across the whole age range. Second, the modal age at death only refers to the most typical age at which most of the life table deaths occur and does not take the distribution of deaths, i.e., dispersion, into account. The contradictory pattern of converging modal age at death and diverging life expectancy can be interpreted in the light of increased dispersion among low educational groups. Their slower increasing life expectancy indicates that more deaths occurred below the modal age at death, which is reflected by the increased dispersion. This is consistent with the finding that greater lifespan variation in lower educated groups is largely determined by conditions causing death at younger ages (van Raalte et al. 2011).

The study found that the life expectancy advantage of high education groups in Sweden and Finland is largely attributable to better progress in reducing mortality at younger ages. However, despite slower health progress at younger ages, increases in the modal age at death in the low education group were either parallel with or even faster than in the high education group. The only exception to this pattern is Swedish females showing simultaneous decreases in the gaps in both measures.

The cause-specific decomposition analyses suggest the potential factors explaining the life expectancy gap in both countries. We found that, besides cardiovascular system diseases, the role of other causes of death (especially cancers) has also increased. The increasing disadvantage of lower educated males in lung cancer mortality should be of particular concern to health policy in Finland. Among females this cause of death remained less important, but it is likely that its role will increase in the near future, in agreement with the "smoking epidemiological transition" (Lopez et al. 1994; Mackenbach 2006). Selected mental and nervous system diseases (including Alzheimer's disease) made smaller but increasingly important contributions, especially among females.

This study focuses on the life expectancy differences between two extreme educational groups (high education group versus low education group). This allowed the identification of the maximal life expectancy difference and the description of ages and causes of death responsible for the disadvantaged position of the low education group. It has been argued that such simple range measures of mortality inequality (e.g., 
maximal life expectancy difference or the Max/Min ratio of the SDRs) are easily interpretable and more understandable for policy makers (Mackenbach and Kunst 1997). However, such an approach suffers from certain limitations. First, the range measures do not account for the distribution of mortality risks across all population groups and therefore do not reflect the total amount of inequality. Second, these measures also do not consider differences in population weights (Shkolnikov et al. 2011).

Taking into account the aforementioned shortcomings of the range-type measures, we checked our conclusion concerning widening mortality inequality using a Gini-type measure (average inter-group difference (AID)). This measure confirms the notable increase in the total amount of mortality inequality by education in the two countries (Table A4).

The rich literature on potential determinants of educational health inequalities mortality in Finland and Sweden may provide some explanation of the observed increase in mortality differences by education at old ages. First, it is necessary to consider the differential impact of the health care system. Despite egalitarian policies it is still possible that the upper socioeconomic groups have an advantage in accessing modern treatment technologies and gain more benefit from prevention programs (Martikainen, Valkonen and Martelin 2001; Martelin 1996). For example, some studies on inequality in access to treatment suggest that in Finland bypass operations were 35\% more common among non-manual than among manual workers (Keskimaki et al. 1997).

Second, numerous health surveys in both countries confirm that poor health status and unhealthy behaviors are much more common in lower socioeconomic classes. For example, in Finland differences in health behaviors (especially in smoking, vegetable consumption, and physical activity) explain about $54 \%$ of the educational differences in cardiovascular mortality among men (Laaksonen et al. 2008). Furthermore, there is some evidence that socioeconomic differences in the prevalence of coronary heart disease risk factors were also increasing (Pekkanen et al. 1995).

The persisting and even increasing socioeconomic differences in the prevalence of smoking in Finland and Sweden seem to explain at least a part of the widening mortality inequality (Lahelma et al. 1997; Cavelaars et al. 2000). Our results, showing that cardiovascular diseases and lung cancer (which are strongly related to smoking) are two key causes of death behind the increase in the life expectancy gap, are in line with the aforementioned findings.

The study found that the importance of the selected mental and nervous system diseases (including Alzheimer's disease) may have increased, especially among females. Epidemiological literature suggests relationships between diet, pharmaceutical behavior, physical and cognitive activity, and the probability of developing Alzheimer's 
disease (Szekely, Breitner and Zandi 2007). It also highlights a significant association between education and an increased risk of developing Alzheimer's disease (Karp et al. 2004). The proposed mechanisms for this association are early life exposure associated with the status of the family and effects of lifelong mental stimulation and neuronal growth (Mortimer and Graves 1993).

The study suffers from two shortcomings and limitations, which should be taken into account in interpretation of the results. The changing definition of educational groups is always an important obstacle for studying long-term trends of mortality inequality. This is the major limitation of our study. We believe that using only three broad educational groups allows us to achieve a better comparability of this data over time and between the two countries. However, it should be taken into account that most of the people aged 65 in 1971-1975 got their education before or during the 1920s. It is obvious that the educational system during this period was different from the system after WWII. Thus, building fully comparable educational categories is not possible, especially for less clearly defined medium and low education categories. It partly depends on how well older people reported their education according to the questions provided in more recent censuses or surveys. Potential evidence of such misclassification and technical difficulties of classifying the education of older people concerns a very small share of people with medium education in Sweden in 1971-1975. The main impact of this misclassification would concern trends in average inter-group difference (AID), which accounts for the population distribution by education. Therefore we conclude that a substantial share of the increase in AID is attributable to the changes in both population composition by education and definition of educational categories.

This study provides some insights into possible determinants of the increase in educational mortality differentials at old age in Finland and Sweden. Obviously, more complex analyses would require more detailed classification of causes of death. However, in this case it would be difficult to minimize potential biases due to: 1) lower quality of registration of causes of death at older ages and 2) changes in the International Classification of Diseases (ICD) or coding practices (Janssen and Kunst 2004; Meslé and Vallin 1996).

The study suggests that several measures of survival should be used to measure socioeconomic mortality differences at old age, capturing specific characteristics of survival at these ages. In addition, more complex Gini-type measures should be used in order to account for both the full amount of mortality inequality and, especially, for notable changes in population structures. The results of this study, along with the fact that growing health inequalities at old ages should be central to public health, call for the implementation of more appropriate health policies, even in egalitarian countries. 


\section{Acknowledgments}

We would like to thank Vladimir M. Shkolnikov (Max Planck Institute for Demographic Research, Rostock, Germany) for his comments and suggestions concerning the first draft of this paper. We would also like to thank Statistics Finland and Statistics Sweden for providing high quality census linked data. We are grateful to Denny Vagero (Centre for Health Equity Studies, Stockholm University, Sweden) for his valuable consultations on the specifics of Swedish data, and to three anonymous reviewers for their comments. 


\section{References}

Andreev, E.M., Shkolnikov, V.M., and Begun, A.Z. (2002). Algorithm for decomposition of differences between aggregate demographic measures and its application to life expectancies, healthy life expectancies, parity-progression ratios and total fertility rates. Demographic Research 7(14): 499-522. doi:10.4054/DemRes.2002.7.14.

Canudas-Romo, V. (2008). The modal age at death and the shifting mortality hypothesis. Demographic Research 19(30): 1179-1204. doi:10.4054/ DemRes.2008.19.30.

Cavelaars, A., Kunst, A.E., Geurts, J.J.M., Crialesi, R., Grotvedt, L., Helmert, U., Lahelma, E., Lundberg, O., Matheson, J., and Mielck, A. (2000). Educational differences in smoking: International comparison. British Medical Journal 320(7242): 1102. doi:10.1136/bmj.320.7242.1102.

Cheung, S.L.K., Robine, J.-M., Tu, E.J.-C., and Caselli, G. (2005). Three dimensions of the survival curve: Horizontalization, verticalization, and longevity extension. Demography 42(2): 243-258. doi:10.1353/dem.2005.0012.

Cheung, S.L.K. and Robine, J.M. (2007). Increase in common longevity and the compression of mortality: The case of Japan. Population Studies 61(1): 85-97. doi:10.1136/bmj.320.7242.1102.

Chiang, C.L. (1984). The life table and its applications. Malabar, Florida: R.E. Krieger Pub. Co.

Hattersley, L. (1997). Expectation of life by social class. In: Drever, F. and Whitehead, M. (eds.). Health inequalities decennial supplement. London: Office for National Statistics.

Hoffmann, R. (2011). Socioeconomic inequalities in old-age mortality: A comparison of Denmark and the USA. Social Science \& Medicine 72(12): 1986-1992. doi:10.1016/j.socscimed.2011.04.019.

Huisman, M., Kunst, A.E., Andersen, O., Bopp, M., Borgan, J.-K., Borrell, C., Costa, G., Deboosere, P., Desplanques, G., and Donkin, A. (2004). Socioeconomic inequalities in mortality among elderly people in 11 European populations. Journal of Epidemiology and Community Health 58(6): 468-475. doi:10.1136/ jech.2003.010496.

Janssen, F. and Kunst, A.E. (2004). ICD coding changes and discontinuities in trends in cause-specific mortality in six European countries, 1950-99. Bulletin of the 
World Health Organization 82(12): 904-913. doi:10.1590/S0042-9686200400 1200006.

Kannisto, V. (2000). Measuring the compression of mortality. Demographic Research 3(6): 1-24. doi:10.4054/DemRes.2000.3.6.

Kannisto, V. (2001). Mode and dispersion of the length of life. Population: An English Selection 13(1): 159-171.

Karp, A., Kåreholt, I., Qiu, C., Bellander, T., Winblad, B., and Fratiglioni, L. (2004). Relation of education and occupation-based socioeconomic status to incident Alzheimer's disease. American Journal of Epidemiology 159(2): 175-183. doi:10.1093/aje/kwh018.

Keskimaki, I., Koskinen, S., Salinto, M., and Aro, S. (1997). Socioeconomic and gender inequities in access to coronary artery bypass grafting in Finland. The European Journal of Public Health 7(4): 392-397. doi:10.1093/eurpub/7.4.392.

Kunst, A.E., Bos, V., Andersen, O., Cardano, M., Costa, G., Harding, S., Hemström, Ö., Layte, R., Regidor, E., and Reid, A. (2004). Monitoring of trends in socioeconomic inequalities in mortality: Experiences from a European project. Demographic Research Special Collection 2(9): 229-254. doi:10.4054/ DemRes.2004.S2.9.

Laaksonen, M., Talala, K., Martelin, T., Rahkonen, O., Roos, E., Helakorpi, S., Laatikainen, T., and Prättälä, R. (2008). Health behaviours as explanations for educational level differences in cardiovascular and all-cause mortality: A followup of 60000 men and women over 23 years. The European Journal of Public Health 18(1): 38-43. doi:10.1093/eurpub/ckm051.

Lahelma, E., Rahkonen, O., Berg, M.-A., Helakorpi, S., Prättälä, R., Puska, P., and Uutela, A. (1997). Changes in health status and health behavior among Finnish adults 1978-1993. Scandinavian Journal of Work Environment and Health 23(S3): 85-90.

Lopez, A.D., Collishaw, N.E., and Piha, T. (1994). A descriptive model of the cigarette epidemic in developed countries. Tobacco Control 3(3): 242-247. doi:10.1136/ tc.3.3.242.

Mackenbach, J.P. (2006). Health inequalities: Europe in profile. Produced by COI for the Department of Health.

Mackenbach, J.P. and Kunst, A.E. (1997). Measuring the magnitude of socio-economic inequalities in health: An overview of available measures illustrated with two 
examples from Europe. Social Science \& Medicine 44(6): 757-771. doi:10.1016/ S0277-9536(96)00073-1.

Marmot, M.G. and McDowall, M.E. (1986). Mortality decline and widening social inequalities. The Lancet 328(8501): 274-276. doi:10.1016/S0140-6736(86)92085-4.

Martelin, T. (1994). Mortality by indicators of socioeconomic status among the Finnish elderly. Social Science \& Medicine 38(9): 1257-1278. doi:10.1016/0277-9536(94)90190-2.

Martelin, T. (1996). Socio-demographic differentials in mortality at older ages in Finland. In: Caselli, G. and Lopez, A.D. (eds.). Health and mortality among elderly populations. Clarendon Press, Oxford: 112-134.

Martelin, T., Koskinen, S., and Valkonen, T. (1998). Sociodemographic mortality differences among the oldest old in Finland. The Journals of Gerontology: Series B 53B(2): S83-S90. doi:10.1093/geronb/53B.2.S83.

Martikainen, P., Valkonen, T., and Martelin, T. (2001). Change in male and female life expectancy by social class: Decomposition by age and cause of death in Finland 1971-95. Journal of Epidemiology and Community Health 55(7): 494-499. doi:10.1136/jech.55.7.494.

Meslé, F. and Vallin, J. (1996). Reconstructing long-term series of causes of death. Historical Methods: A Journal of Quantitative and Interdisciplinary History 29(2): 72-87. doi:10.1080/01615440.1996.10112731.

Mirowsky, J. and Ross, C.E. (2003). Education, social status, and health. New York: Aldine de Gruyter.

Mortimer, J.A. and Graves, A.B. (1993). Education and other socioeconomic determinants of dementia and Alzheimer's disease. Neurology 43(8, Supplement 4): S39-S44.

Olausson, P.O. (1991). Mortality among the elderly in Sweden by social class. Social Science \& Medicine 32(4): 437-440. doi:10.1016/0277-9536(91)90345-D.

Pekkanen, J., Uutela, A., Valkonen, T., Vartiainen, E., Tuomilehto, J., and Puska, P. (1995). Coronary risk factor levels: Differences between educational groups in 1972-87 in eastern Finland. British Medical Journal 49(2): 144-149. doi:10.1136/jech.49.2.144.

R Development Core Team (2010). R: A Language and Environment for Statistical Computing. Vienna, Austria: R Foundation for Statistical Computing. 
Shkolnikov, V.M., Andreev, E.M., Jdanov, D.A., Jasilionis, D., Kravdal, Ã., Vågerö, D., and Valkonen, T. (2011). Increasing absolute mortality disparities by education in Finland, Norway and Sweden, 1971-2000. Journal of Epidemiology and Community Health 66(4): 372-378. doi:10.1136/jech.2009.104786.

Strand, B.H., Grøholt, E.-K., Steingrímsdóttir, Ó.A., Blakely, T., Graff-Iversen, S., and Næss, Ø. (2010). Educational inequalities in mortality over four decades in Norway: Prospective study of middle aged men and women followed for cause specific mortality, 1960-2000. BMJ: British Medical Journal 340: 1-10. doi:10.1136/bmj.c654.

Strand, B.H., Kunst, A., Huisman, M., Menvielle, G., Glickman, M., Bopp, M., Borell, C., Borgan, J.K., Costa, G., and Deboosere, P. (2007). The reversed social gradient: Higher breast cancer mortality in the higher educated compared to lower educated. A comparison of 11 European populations during the 1990s. European Journal of Cancer 43(7): 1200-1207. doi:10.1016/j.ejca.2007.01.021.

Szekely, C.A., Breitner, J.C.S., and Zandi, P.P. (2007). Prevention of Alzheimer's disease. International Review of Psychiatry 19(6): 693-706. doi:10.1080/ 09540260701797944.

Valkonen, T. (1993). Problems in the measurement and international comparison of socio-economic differences in mortality. Social Science \& Medicine 36(4): 409418. doi:10.1016/0277-9536(93)90403-Q.

Valkonen, T. (2001). Trends in differential mortality in European countries. In: Vallin, J., Meslé, F., and Valkonen, T. (eds.). Trends in mortality and differential mortality. Strasbourg: Council of Europe Publishing: 185-322.

Valkonen, T., Martelin, T., Rimpelä, A., Notkola, V., and Savela, S. (1993). Socioeconomic mortality differences in Finland 1981-1990. Statistics Finland.

Valkonen, T., Sihvonen, A.-P., and Lahelma, E. (1997). Health expectancy by level of education in Finland. Social Science \& Medicine 44(6): 801-808. doi:10.1016/ S0277-9536(96)00190-6.

van Raalte, A.A., Kunst, A.E., Deboosere, P., Leinsalu, M., Lundberg, O., Martikainen, P., Strand, B.H., Artnik, B., Wojtyniak, B., and Mackenbach, J.P. (2011). More variation in lifespan in lower educated groups: Evidence from 10 European countries. International Journal of Epidemiology 40(6). doi:10.1093/ije/dyr146. 
Zarulli, Jasilionis \& Jdanov: Changes in educational differentials in old-age mortality in Finland and Sweden

\section{Appendix}

Table A1: Groups of causes of death used in the analysis, according to international classification

\begin{tabular}{|c|c|c|}
\hline & $\begin{array}{l}\text { 1996-2000 } \\
\text { ICD-10 }\end{array}$ & $\begin{array}{l}\text { 1971-1975 } \\
\text { ICD-8 }\end{array}$ \\
\hline $\begin{array}{l}\text { Cerebrovascular, } \\
\text { circulatory diseases }\end{array}$ & I60-I69, I00-I15, I26-I28, I70-I99 & $\begin{array}{l}430-434,436-438,2891-2893, \\
390-404,426440-4441,4443- \\
4458,447-458\end{array}$ \\
\hline Heart diseases & I20-I25, I30-I425, I427-I52 & $410-414,420-425,427-429$ \\
\hline Lung cancer & C32-C34 & $161-162$ \\
\hline Breast cancer & C50 & 174 \\
\hline Prostate cancer & C61 & 185 \\
\hline Stomach cancer & C16 & 151 \\
\hline Intestine cancer & C19-C19, C20-C21 & $153,1540,1541-1542$ \\
\hline Uterus cancer & C53, C54-C55 & 180,182 \\
\hline Other neoplasms & $\begin{array}{l}\text { C00-C14, C15, C22, C25, C43, C56, } \\
\text { C64, C67, C81-C96, C17, C23-C24, } \\
\text { C26-C31, C37-C41, C44-C49, C51- } \\
\text { C52, C57-C60, C62-C63, C65-C66, } \\
\text { C68-C80, C97, D00-D48 }\end{array}$ & $\begin{array}{l}140-149,150,155,157,172,1830, \\
1890,188,200-207,2755,152, \\
156,158-160,163-171,173,181, \\
1831-184,186-187,1891-199, \\
208-239\end{array}$ \\
\hline $\begin{array}{l}\text { Mental disorders and the } \\
\text { diseases of nervous system } \\
\text { (including Alzheimer's } \\
\text { disease), senility }\end{array}$ & $\begin{array}{l}\text { F01, F03, G30, R54, } \\
\text { G00-G29, G310.0-G311, G31.8- } \\
\text { G620, G622-G720, G722-H95 }\end{array}$ & $\begin{array}{l}290,794,320-332,331-389,435 \\
7832\end{array}$ \\
\hline $\begin{array}{l}\text { Respiratory, } \\
\text { infectious diseases }\end{array}$ & A00-B99, J65, J00, J64, J66-J99 & $\begin{array}{l}000-033,0341-134,1362759 \text { (if } \\
\text { year of death >=1984, 5281), } \\
0340,460-519,7960\end{array}$ \\
\hline Other diseases & $\begin{array}{l}\text { E00-E90 } \\
\text { K00-K291, K293-K67, K71-K85, } \\
\text { K861-K93, N00-N99, Q00-Q99, } \\
\text { D50-D89, F00, F02, F04-F09, F11- } \\
\text { F99, L00-M99, O00-O353, O355- } \\
\text { P042, P044-P96, R00-R53, R55-595 }\end{array}$ & $\begin{array}{l}269,520-5280,5282-570,5719- \\
576,577,580-629,7860,7862, \\
740-759,135,2652,2750-2751, \\
280-2890,2894-289,292-302, \\
304-315,4459,446,630-738,760- \\
7831,7833-785,7861,7863-793, \\
795-796\end{array}$ \\
\hline Accidental falls & W00-W19 & E880-E885, E887 \\
\hline Suicides & X60-X84, Y870 & E950-E959 \\
\hline Other external causes & $\begin{array}{l}\text { F10, G312, G4051, G621, G721, } \\
\text { I426, K292, K70, K860, K8600, } \\
\text { 0354, P043, X45, V01-X44, X46-Y89 } \\
\text { (excluded W00-W19 and X60-X84, } \\
\text { Y870) }\end{array}$ & $\begin{array}{l}\text { 291, 303, 5710, 577, males E860, } \\
\text { E800-E859, E861-E999 (excluded } \\
\text { E880-E885, E887, E950-E959) }\end{array}$ \\
\hline III defined, unknown diseases & R96-R99 & $795,7961-7969$ \\
\hline
\end{tabular}


Table A2: Men: Age and cause of death components in life expectancy gap in Finland and Sweden in 1971-1975 and 1996-2000

\begin{tabular}{|c|c|c|c|c|c|c|c|c|c|c|c|c|}
\hline \multirow[t]{3}{*}{ Country and Cause } & \multicolumn{6}{|c|}{ 1971-1975 } & \multicolumn{6}{|c|}{$1996-2000$} \\
\hline & \multicolumn{6}{|c|}{ Age group } & \multicolumn{6}{|c|}{ Age group } \\
\hline & $65-69$ & $70-74$ & $75-79$ & $80-84$ & $85+$ & Tot. & $65-69$ & $70-74$ & $75-79$ & $80-84$ & $85+$ & Tot. \\
\hline \multicolumn{13}{|l|}{ Sweden } \\
\hline $\begin{array}{l}\text { Cerebrovascular, } \\
\text { circulatory diseases }\end{array}$ & -0.037 & -0.029 & -0.040 & -0.054 & -0.048 & -0.208 & -0.085 & -0.091 & -0.102 & -0.084 & -0.075 & -0.437 \\
\hline Heart diseases & -0.221 & -0.159 & -0.193 & -0.160 & -0.062 & -0.796 & -0.251 & -0.281 & -0.251 & -0.182 & -0.218 & -1.181 \\
\hline Lung cancer & -0.011 & -0.018 & 0.001 & 0.012 & -0.001 & -0.017 & -0.058 & -0.042 & -0.016 & -0.008 & -0.010 & -0.134 \\
\hline Prostate cancer & -0.003 & 0.003 & -0.013 & -0.009 & 0.034 & 0.012 & -0.009 & 0.003 & -0.010 & 0.001 & 0.007 & -0.008 \\
\hline Stomach cancer & -0.015 & -0.036 & -0.028 & -0.009 & -0.013 & -0.100 & -0.013 & -0.013 & -0.009 & -0.010 & -0.006 & -0.050 \\
\hline Intestine cancer & 0.007 & 0.008 & 0.024 & -0.001 & -0.006 & 0.033 & -0.016 & -0.014 & -0.005 & -0.005 & -0.001 & -0.040 \\
\hline Other neoplasms & -0.001 & -0.010 & 0.006 & 0.021 & 0.016 & 0.033 & -0.018 & -0.049 & -0.022 & -0.017 & -0.004 & -0.110 \\
\hline $\begin{array}{l}\text { Mental disorders, } \\
\text { Alzheimer's, senility }\end{array}$ & 0.002 & -0.002 & -0.003 & -0.003 & -0.003 & -0.010 & -0.002 & -0.008 & -0.011 & -0.003 & -0.003 & -0.027 \\
\hline $\begin{array}{l}\text { Respiratory, } \\
\text { infectious diseases }\end{array}$ & -0.024 & -0.040 & -0.054 & -0.039 & -0.013 & -0.169 & -0.048 & -0.060 & -0.063 & -0.078 & -0.076 & -0.325 \\
\hline Other diseases & -0.050 & -0.036 & -0.037 & -0.023 & -0.021 & -0.167 & -0.064 & -0.055 & -0.043 & -0.038 & -0.063 & -0.263 \\
\hline Accidental falls & 0.003 & -0.004 & -0.004 & -0.001 & 0.005 & -0.002 & 0.000 & -0.007 & -0.003 & -0.001 & 0.000 & -0.011 \\
\hline Suicides & -0.003 & 0.001 & -0.002 & 0.001 & 0.002 & -0.001 & -0.014 & -0.004 & -0.005 & -0.001 & -0.003 & -0.027 \\
\hline $\begin{array}{l}\text { Other external } \\
\text { causes }\end{array}$ & -0.008 & -0.007 & -0.009 & 0.002 & 0.001 & -0.022 & -0.013 & -0.003 & -0.008 & -0.006 & -0.002 & -0.032 \\
\hline $\begin{array}{l}\text { Ill-defined, } \\
\text { unknown diseases }\end{array}$ & -0.004 & 0.001 & -0.001 & 0.001 & -0.004 & -0.007 & -0.012 & -0.009 & -0.002 & -0.002 & -0.002 & -0.028 \\
\hline Tot. & -0.365 & -0.327 & -0.352 & -0.263 & -0.114 & -1.422 & -0.602 & -0.634 & -0.548 & -0.434 & -0.455 & -2.673 \\
\hline \multicolumn{13}{|l|}{ Finland } \\
\hline $\begin{array}{l}\text { Cerebrovascular, } \\
\text { circulatory diseases }\end{array}$ & -0.070 & -0.023 & -0.013 & -0.017 & 0.007 & -0.115 & -0.105 & -0.092 & -0.093 & -0.044 & -0.028 & -0.361 \\
\hline Heart diseases & -0.290 & -0.234 & -0.097 & -0.066 & -0.109 & -0.796 & -0.329 & -0.347 & -0.219 & -0.212 & -0.167 & -1.274 \\
\hline Lung cancer & -0.180 & -0.064 & -0.016 & -0.019 & -0.003 & -0.281 & -0.149 & -0.131 & -0.060 & -0.038 & -0.019 & -0.397 \\
\hline Prostate cancer & 0.009 & 0.018 & 0.015 & 0.018 & -0.001 & 0.059 & 0.001 & -0.017 & 0.003 & 0.010 & 0.002 & -0.001 \\
\hline Stomach cancer & -0.036 & -0.041 & -0.030 & -0.007 & -0.005 & -0.118 & -0.022 & -0.009 & -0.006 & -0.009 & -0.010 & -0.056 \\
\hline Intestine cancer & 0.033 & 0.001 & 0.000 & 0.007 & 0.000 & 0.041 & 0.001 & 0.009 & 0.010 & 0.009 & 0.011 & 0.040 \\
\hline Other neoplasms & 0.004 & -0.013 & 0.024 & -0.011 & -0.017 & -0.014 & -0.055 & -0.031 & -0.021 & -0.018 & 0.003 & -0.122 \\
\hline $\begin{array}{l}\text { Mental disorders, } \\
\text { Alzheimer's', senility }\end{array}$ & 0.004 & -0.002 & -0.002 & 0.000 & 0.001 & 0.001 & -0.010 & -0.009 & -0.023 & -0.001 & -0.006 & -0.048 \\
\hline $\begin{array}{l}\text { Respiratory, } \\
\text { infectious diseases }\end{array}$ & -0.159 & -0.182 & -0.082 & -0.077 & -0.036 & -0.535 & -0.104 & -0.106 & -0.150 & -0.130 & -0.138 & -0.628 \\
\hline Other diseases & 0.004 & -0.001 & -0.013 & -0.001 & -0.013 & -0.025 & -0.084 & -0.017 & -0.021 & -0.040 & -0.029 & -0.191 \\
\hline Accidental falls & 0.001 & 0.014 & -0.004 & -0.008 & -0.002 & 0.001 & -0.015 & -0.004 & 0.003 & -0.008 & -0.003 & -0.026 \\
\hline Suicides & -0.013 & -0.004 & -0.007 & -0.005 & -0.002 & -0.031 & -0.012 & -0.014 & -0.007 & -0.004 & -0.005 & -0.043 \\
\hline $\begin{array}{l}\text { Other external } \\
\text { causes }\end{array}$ & -0.025 & -0.019 & -0.019 & 0.003 & -0.008 & -0.068 & -0.012 & -0.024 & -0.015 & -0.002 & 0.000 & -0.053 \\
\hline $\begin{array}{l}\text { Ill-defined, } \\
\text { unknown diseases }\end{array}$ & -0.008 & 0.006 & 0.006 & -0.007 & -0.004 & -0.007 & -0.003 & -0.006 & -0.004 & -0.001 & -0.005 & -0.019 \\
\hline Tot. & -0.726 & -0.544 & -0.237 & -0.190 & -0.192 & -1.889 & -0.898 & -0.797 & -0.601 & -0.488 & -0.395 & -3.180 \\
\hline
\end{tabular}


Zarulli, Jasilionis \& Jdanov: Changes in educational differentials in old-age mortality in Finland and Sweden

Table A3: Women: Age and cause of death components in life expectancy gap in Finland and Sweden in 1971-1975 and 1996-2000

\begin{tabular}{|c|c|c|c|c|c|c|c|c|c|c|c|c|}
\hline \multirow[t]{3}{*}{ Country and Cause } & \multicolumn{6}{|c|}{ 1971-1975 } & \multicolumn{6}{|c|}{$1996-2000$} \\
\hline & \multicolumn{6}{|c|}{ Age group } & \multicolumn{6}{|c|}{ Age group } \\
\hline & $65-69$ & $70-74$ & $75-79$ & $80-84$ & $85+$ & Tot. & $65-69$ & $70-74$ & $75-79$ & $80-84$ & $85+$ & Tot. \\
\hline \multicolumn{13}{|l|}{ Sweden } \\
\hline $\begin{array}{l}\text { Cerebrovascular, } \\
\text { circulatory diseases }\end{array}$ & -0.019 & -0.081 & -0.100 & -0.046 & -0.067 & -0.312 & -0.071 & -0.104 & -0.104 & -0.150 & -0.259 & -0.689 \\
\hline Heart diseases & -0.184 & -0.297 & -0.290 & -0.196 & -0.167 & -1.134 & -0.139 & -0.176 & -0.189 & -0.189 & -0.498 & -1.192 \\
\hline Lung cancer & 0.002 & 0.011 & -0.005 & 0.009 & -0.003 & 0.014 & -0.039 & -0.021 & -0.015 & 0.000 & 0.003 & -0.072 \\
\hline Breast cancer & 0.007 & -0.001 & 0.002 & 0.004 & -0.002 & 0.011 & 0.001 & 0.008 & 0.012 & 0.013 & 0.005 & 0.039 \\
\hline Stomach cancer & -0.010 & -0.022 & -0.013 & -0.024 & -0.023 & -0.092 & -0.006 & -0.007 & -0.005 & -0.010 & -0.009 & -0.036 \\
\hline Intestine cancer & -0.008 & 0.002 & -0.003 & 0.034 & 0.027 & 0.052 & -0.003 & -0.012 & -0.016 & -0.003 & -0.024 & -0.058 \\
\hline Uterus cancer & -0.010 & -0.002 & -0.014 & -0.008 & 0.021 & -0.014 & -0.005 & -0.010 & 0.001 & -0.002 & -0.002 & -0.017 \\
\hline Other neoplasms & 0.016 & 0.018 & -0.050 & -0.043 & 0.003 & -0.056 & -0.057 & -0.047 & -0.049 & -0.013 & -0.029 & -0.195 \\
\hline $\begin{array}{l}\text { Mental disorders, } \\
\text { Alzheimer's, senility }\end{array}$ & -0.002 & -0.004 & -0.001 & 0.001 & -0.026 & -0.030 & -0.004 & -0.014 & -0.015 & -0.019 & -0.126 & -0.177 \\
\hline $\begin{array}{l}\text { Respiratory, } \\
\text { infectious diseases }\end{array}$ & -0.028 & -0.033 & -0.036 & -0.043 & 0.006 & -0.134 & -0.051 & -0.055 & -0.043 & -0.052 & -0.177 & -0.377 \\
\hline Other diseases & -0.037 & -0.096 & -0.067 & -0.053 & -0.059 & -0.312 & -0.054 & -0.039 & -0.060 & -0.051 & -0.124 & -0.328 \\
\hline Accidental falls & 0.000 & -0.006 & -0.028 & 0.003 & -0.019 & -0.051 & -0.001 & -0.002 & -0.003 & -0.003 & 0.002 & -0.007 \\
\hline Suicides & -0.003 & 0.007 & 0.001 & 0.003 & -0.001 & 0.007 & 0.000 & 0.002 & -0.001 & 0.002 & 0.004 & 0.006 \\
\hline $\begin{array}{l}\text { Other external } \\
\text { causes }\end{array}$ & 0.024 & -0.008 & -0.001 & -0.002 & -0.005 & 0.008 & -0.003 & -0.005 & 0.010 & -0.010 & 0.001 & -0.006 \\
\hline $\begin{array}{l}\text { Ill-defined, } \\
\text { unknown diseases }\end{array}$ & 0.001 & -0.018 & 0.007 & -0.016 & -0.007 & -0.034 & -0.012 & -0.009 & 0.000 & -0.014 & -0.007 & -0.043 \\
\hline Tot. & -0.250 & -0.529 & -0.597 & -0.378 & -0.322 & -2.077 & -0.444 & -0.491 & -0.477 & -0.500 & -1.241 & -3.153 \\
\hline \multicolumn{13}{|l|}{ Finland } \\
\hline $\begin{array}{l}\text { Cerebrovascular, } \\
\text { circulatory diseases }\end{array}$ & -0.087 & -0.152 & -0.127 & -0.087 & -0.057 & -0.510 & -0.054 & -0.083 & -0.099 & -0.090 & -0.092 & -0.418 \\
\hline Heart diseases & -0.257 & -0.201 & -0.212 & -0.144 & -0.115 & -0.929 & -0.134 & -0.242 & -0.211 & -0.255 & -0.233 & -1.076 \\
\hline Lung cancer & 0.009 & 0.005 & 0.003 & 0.001 & 0.000 & 0.018 & -0.014 & -0.024 & -0.009 & 0.001 & -0.009 & -0.054 \\
\hline Breast cancer & 0.040 & 0.009 & 0.005 & 0.006 & 0.002 & 0.062 & 0.024 & 0.007 & 0.029 & 0.007 & 0.003 & 0.070 \\
\hline Stomach cancer & -0.026 & -0.029 & -0.030 & -0.019 & -0.013 & -0.116 & -0.015 & -0.004 & -0.007 & -0.007 & -0.008 & -0.041 \\
\hline Intestine cancer & 0.001 & -0.006 & 0.011 & 0.000 & -0.007 & -0.001 & -0.010 & 0.001 & 0.003 & 0.012 & -0.007 & -0.001 \\
\hline Uterus cancer & -0.004 & 0.004 & 0.027 & 0.003 & -0.001 & 0.029 & 0.001 & 0.012 & 0.005 & 0.003 & -0.004 & 0.017 \\
\hline Other neoplasms & -0.036 & 0.008 & 0.027 & -0.024 & -0.005 & -0.030 & -0.015 & -0.091 & -0.032 & 0.012 & -0.041 & -0.167 \\
\hline $\begin{array}{l}\text { Mental disorders, } \\
\text { Alzheimer's, senility }\end{array}$ & 0.003 & -0.002 & 0.006 & 0.006 & -0.021 & -0.008 & -0.008 & -0.008 & -0.017 & 0.007 & -0.022 & -0.048 \\
\hline $\begin{array}{l}\text { Respiratory, } \\
\text { infectious diseases }\end{array}$ & -0.031 & -0.067 & -0.056 & -0.085 & -0.058 & -0.297 & -0.028 & -0.067 & -0.060 & -0.044 & -0.100 & -0.299 \\
\hline Other diseases & -0.045 & -0.075 & -0.036 & -0.053 & 0.004 & -0.204 & -0.025 & -0.039 & -0.041 & -0.056 & -0.084 & -0.244 \\
\hline Accidental falls & -0.010 & -0.006 & -0.018 & 0.001 & 0.038 & 0.005 & -0.003 & -0.012 & -0.006 & 0.006 & 0.024 & 0.008 \\
\hline Suicides & 0.004 & -0.002 & 0.004 & -0.001 & 0.000 & 0.004 & 0.002 & 0.001 & 0.002 & 0.004 & 0.001 & 0.009 \\
\hline $\begin{array}{l}\text { Other external } \\
\text { causes }\end{array}$ & -0.006 & 0.004 & 0.004 & 0.005 & 0.000 & 0.006 & -0.002 & -0.004 & 0.001 & 0.008 & -0.002 & 0.001 \\
\hline $\begin{array}{l}\text { Ill-defined, } \\
\text { unknown diseases }\end{array}$ & 0.002 & -0.001 & -0.010 & 0.009 & 0.006 & 0.007 & -0.008 & -0.009 & -0.002 & 0.010 & -0.001 & -0.011 \\
\hline Tot. & -0.443 & -0.512 & -0.402 & -0.382 & -0.225 & -1.962 & -0.288 & -0.563 & -0.443 & -0.385 & -0.574 & -2.253 \\
\hline
\end{tabular}


Table A4: Changes in average inter-group difference (AID) at ages over 65 in Finland and Sweden from 1971-1975 to 1996-2000 (per 1000 person years)

\begin{tabular}{lllll}
\hline & Sweden & & Finland & \\
\hline & Males & Females & Males & Females \\
$1971-1975$ & 0.39 & 0.16 & 1.47 & 0.83 \\
$1996-2000$ & 2.02 & 1.02 & 2.31 & 0.93 \\
\hline
\end{tabular}


Zarulli, Jasilionis \& Jdanov: Changes in educational differentials in old-age mortality in Finland and Sweden 